\title{
Transition from High-School to University: Obstacles and Difficulties
}

\author{
Bouchaib Eddaif ${ }^{1}$, Driss Boriky ${ }^{2}$, Fatih Mustapha ${ }^{3}$, Mounir Sadik $^{4}$, \\ Mohamed Amine Hanine ${ }^{5}$, Radouane Kasour ${ }^{6}$, Mohammed Moustad ${ }^{7}$ and \\ Mohammed Talbi ${ }^{8}$. \\ ${ }^{1-3-4-5-6-8}$ Observatoire de recherche en didactique et pédagogie universitaire \\ ${ }^{1-2}$ Laboratoire de Chimie Analytique et Physicochimie des Matériaux LCAPM. \\ ${ }^{3-7}$ Laboratoire d'Ingénierie et MATériaux (LIMAT)
}

\begin{abstract}
Transition from high-school to university is a hard moment for students following scientific studies, particularly at math. It's a delicate situation renown at an international level. The question of improving transition from secondary-school to university is not new. It has been tackled by numerous mathematicians and pedagogues. For this purpose, an educational and scientific meeting was held on February 27th,2016 at Abderrahmane Belkorchi High-school, under the aegis of the Regional Directory of Moulay Rachid and in partnership with the Faculty of Sciences, Ben M'Sik,Casablanca. The procedure undertaken is based on workshops for diverse scientific disciplines. Invited for the event were teaching staff, inspectors, educational researchers, high-school and university teachers. An analysis on the basis of a methodology of interfering participants in the workshops based on the knowledge taught, methods of teaching and the psychological considerations of the learner have been made. Finally, on the basis of the effective results obtained, some suggestions have been proposed.
\end{abstract}

Keywords: High-school-university transition, Obstacles, Difficulties, Foreign language.

\section{Introduction}

After an Arabic -based policy adopted by the State in the early 80s, the teaching of the scientific disciplines in the public sector for primary and secondary levels started being delivered in Arabic ; whereas at university the learning of the basic subjects continued to be delivered in French. Thereby, since the academic year 1990_91, Moroccan Science Faculties have begun receiving baccalaureate students who had their teaching delivered in Arabic. Conceivably, a problem of linguistic transition, manifested at one extreme by a fleeing towards Arabic-based scientific options and at another extreme by difficulties and learning obstacles in the acquisition of scientific knowledge, surfaced. The training of high-school students and university students calls us as educators, as we have to give their objectives in the renewed teaching-learning perspective the meaning that they deserve to immunize our future students. Through this meeting we will show the difficulties and obstacles which the future university student encounters during the course of high-school-university transition. We will also know the preliminary gaps between high school and university in order to devise some outlets.

\section{Objective}

The aim of the meeting is to identify the obstacles and difficulties which inhibit the so-called high-schooluniversity transition of the future university-student.

\section{Problematic}

Freshmen of scientific disciplines fail university requirements steadily. By this we do not only mean their impoverished scientific insight but also that the majority of them are at a loss in terms of methods to follow or efforts to make. Notwithstanding the questioning of their abilities, it stands to reason that the students are confronted with tremendous difficulties to keep abreast of the first year curriculum.

For this, important questions arise:

$>$ What are then the obstacles and difficulties encountered by the high school -university student?

$>$ And how can they be resolved?

Maybe the problem is due to:

\section{Hypotheses}

$>$ Teaching methods at the university which differ from those used at high school;

$>$ The use of Arabic in high school and French at the university;

$>$ Badly-oriented students. 


\subsection{High school- university transition}

\section{Theoretical Framework}

The transition from high school to university is known, at an international level, as being a difficukt time for students. This has been formalized in France. The Hetzel report(university/employment national debate commission,2006) reveals significant failure rates in first year at university(less than a student out of two move to second year). A report by the Academy of Sciences(2007) gives possible causes to account for that failure: heterogeneity of the public(mainly due to the lack of recruiting criteria at entrance), lack of insight into the nature of university studies in the student( prerequisites, work pace), lack of framework training(so much nonaccompanied individual work) and material difficulties in some students 1. It is not an exclusive problem of France: other foreign university researchers have observed the same phenomenon and advanced multiple causes as well. Likewise, in a recent study (Sauvé,Debeurne,Wright, Racette and Pépin,2009) about inability to pursue university education, Canadian teachers underline five types of explaining hypotheses: deficiencies related to prerequisites, deficiencies in strategic competencies, problems of institutional integration, material difficulties and ,ultimately, motivational problems. They also make the hypothesis that the decision to give up university studies frequently stems from multiple converging causes.

\subsection{Orientation}

A good orientation is clearly a success, in the sense that it allows the improvement of students' information by creating a dynamic high school-university relation. It further raises consciousness as to the importance of challenges related to it: allowing each student to follow a course of training that is consonant with their profile and their professional integration, value university training as an integral way towards success and employment.

\subsection{Obstacles}

"A pedagogical obstacle is a representation of the duty,engendered by former learning, being the cause of systematic mistakes and inhibiting present learning".1

"There is an obstacle when the new conceptions to form contradict the learner's well-established former conceptions"(Bednarz, Garnier,1989).

We may think that this concept was created by analogy to the epistemological obstacles described by Gaston Bachelard2. A pedagogical obstacle is thereby a negative representation of the learning task, engendered by a prior learning and inhibiting a new learning experience. There is an obstacle then when the "newer conceptions" to be acquired contradict the "former conceptions" of the learner.

\subsection{Difficulties}

According to Guy Broussou, a difficulty is a condition, an aspect of a situation which significantly increases the probability of inability to respond or responding erroneously on the part of acting individuals in a given situation. This acting individual may be a student, but might as well be a teacher who experiences a certain difficulty to acquire the learning he is conveying.

\subsection{French as a foreign language}

Moroccan university students of scientific branches have difficulty building up solid knowledge in French in view of the fact that all scientific subjects had been delivered exclusively in Arabic in middle school and secondary school. Due to this state of failure, we will inquire, during this colloquium, about which French is taught in Algerian universities in the so-called scientific and technical branches: "French for specific objective"(FSO), "French for a university objective"(FUO)or "French as a foreign language"(FFL). What "French" is most appropriate to facilitate not only their building of discipline-based knowledge but also the acquisition of all the requisite competencies for the learning of a language?

\subsection{Orientation workshop}

\section{Practical Framework(Workshops)}

Under the supervision of Dr.Mohamed Radid and the inspector of orientation, Hassan Ait Elbour, and with the presence of 2 nd year bac, the discussion was divided into three axes:

The 1st axis focused on:

$>$ The educational structure and the calculation method of the average by taking the faculty of sciences as a model;

$>$ The importance of a good orientation during the transition from high-school to university.

The 2nd axis pinned down the student's adaptation at university, a period that calls for serious work in order to pass and get the desired results. The 3rd axis gave so much importance to the delicacies of challenges in every scientific option before the final choice in order to avoid all hazardous orientation leading to failure. 
Ultimately, an orientation team is judged necessary to accompany the transition from high-school to university. Thus, the workshop fixed another meeting date in Mach 2017 in order to study the following problems:

Post-baccalaureate studies perspectives;

$>$ Place of the university so as to choose the future students;

$>$ Difficulties encountered by the student at the university.

\subsection{Math workshop}

It was co-supervised by Dr. Achtaich and the inspector, Ejilali Echardoudi.

In the first place, the students stated the encountered problems:

$>$ Insufficient communication between learner and teacher in high-school and absence of communication at university;

$>$ Weak output due to over-crowdedness and chatting;

$>$ Traditional teaching methods based on quantity without any qualitative input, which target the covering of the course regardless of acquisition;

$>$ Doubling the languages of study, Arabic in high-school and French at university;

$>$ Math teaching in high-school is teacher-based in contrast to university;

$>$ Lack of ICT both in high-school and university;

$>$ Psychological problems in the learner following the expression of his point of view, which is generally refused by the teacher;

$>$ Stress and fear during exam periods(regional, national or modular).

Secondly, the teachers were asked to formulate the problems and difficulties encountered:

$>$ Lack of learner motivation;

$>$ The teacher does everything;

$>$ The prerequisites are not acquired;

$>$ Cumulated problems of threshold, school map and orientation during movement from one class to another;

$>$ Private lessons make the learner inert in class;

$>$ Reforms at high-school have stopped;

$>$ Insufficient or lacking translation classes;

$>$ Negative effect of over-crowdedness on communication.

Thirdly, prospective solutions were given:

$>$ The identification of high-school and university students is needed;

$>$ Listening to the learner and the adoption of newer communication mechanisms in order to simplify the relationship between the learner and the teacher;

$>$ Acquaint the student with research and strengthen his/her self-awareness;

$>$ Adopting local solutions in all reforms and adapting teaching methods.

\subsection{Physiscs and chemistry workshop}

Under Dr. Said Eljamali's supervision and the inspector Elmaati Fatnane, high-school and university students stated the difficulties encountered:

$>$ The introduction of a new language at the university;

$>$ Insufficient and unadjusted translation hours, which does not facilitate transition from Arabic to French;

$>$ Over-crowdedness in class impoverishes output;

$>$ Experimental concepts and phenomena are ill-acquired;

$>$ A national exam which is not consonant with its duration.

Then, the teachers explained these problems by:

$>$ Arabic-based teaching in high-school;

The change of curriculum;

$>$ The distance between math and physics;

$>$ The change of teaching methods;

$>$ Problems of over-crowdedness in class;

$>$ Lack of equipment for experiments and absence of groups, which lowers students' level at physics.

It's worthwhile to mention that some teachers have linked the linguistic problems encountered to the general deterioration of languages. 
Finally, recommendations were made:

$>$ Return of trust between students, subject and environment, especially the university;

$>$ Revision of teaching methods;

$>$ Orientation based on the students 'skills away from parents' influence;

$>$ A scientific pension as a point of support is required;

$>$ Building up bridges between primary, secondary and university in the teaching of physics;

$>$ Self-study motivation.

$>$ Sorting out the phenomenon of overcrowding in class.

$>$ Setting up a partnership between high school and university.

\subsection{Biology and geology workshops}

Supervised by teacher Benali Abdelhak and Sofia Star, the speakers cited the difficulties related to the high-school-university student transition and his/her integration into university life. They adopted a unanimous proposal that the problems encountered by the student during this period are:

$>$ Scientific, related to knowledge, prerequisites and methods of teaching;

$>$ Psychic and social ;

$>$ Practical, due to the absence of practical workshops, groups and lack of special rooms for biology an geology;

$>$ Linguistic.

Later, accounts by teachers were made as follows:

$>$ The common trunk and the first year bac which have to be a bridge of reinforcement of knowledge are not because of the insufficiency of translation (1h per week), which cripples the student's ability to cope with French at the university.

$>$ The psychic and social aspect of the student are related to:

Lack of hope in the absence of a clear vision of university studies,

Poverty and family problems

Drug problems;

The absence of listening centers;

$\square$ French which is quite nightmarish to the student.

$>$ The transition between class and amphitheatres leaves the student in difficulties of adaptation to the methods of university teaching.

Finally, and faced with this impasse, the members of the workshop were sure that the resolution of such problems requires an effective policy integrating all the actors of education.

\subsection{Economy workshop:}

Under the supervision of the pedagogical inspector Asmaa Haydi and the aggregated doctor Snadrou Khalid, the workshop members mention the difficulties encountered by the student after the baccalaureate at the university according to three levels:

$>$ Oral communication and writing prove the problems of French and Arabic languages, which consequently leaves the student under real suffering.

$>$ The skills not acquired by the student, due to the lack or insufficiency of activities motivating the development of research tools and scientific discussions, which yields a student without critical thinking or analysis.

$>$ The teaching method is traditional. The teacher is the only source of information, but in fact, the learner must be at the center of the teaching-learning operation in order to acquire the skills needed to build the knowledge leading to autonomy.

Later, some main causes of these obstacles and difficulties were given:

$\square$ For the learner:

Language problems and lack of orientation give a choice of branch not adapted to the skills of the student;

$\square$ For the teacher:

- The loaded course and the traditional teaching method leave the teacher in sufferance;

- Lack of coordination between high school teachers, university teachers, school orientating staff and the environment;

- $\quad$ Lack of in-service training for teachers.

$\square$ For administratos:

Lack of ongoing training, guidance and coordination; they are interested only in the evaluation of the student.

$\square$ For the environment:

It does not play its main role in the teaching-learning process so the problems cited are of a relational type: family-school, family-student and family-teacher. 
Finally, solutions have been proposed:

$>$ Openness on the learner by all actors of education to have mutual trust;

$>$ Revision of guidance methods by appropriate criteria to encourage students to make the right choice.

\section{Conclusion And Perspectives}

In conclusion to have a successful transition between high school and university, the solutions proposed by the members of workshops are to be taken into account:

$>$ The setting of the objectives of pupils and university students is requested;

$>$ Listening to the learner and adopting new communication mechanisms to simplify the relationship between learner and teacher;

$>$ Adapt the student to research and foster self-awareness in the learner;

$>$ Adopt local solutions in any reform and adapt teaching methods far from any projection;

$>$ Restoring trust between students, subject and environment especially the university;

$>$ Revision of teaching methods;

$>$ Orientation based on the students 'skills away from parents' influence;

$>$ A scientific pension is required for support;

$>$ Building bridges between primary-school, secondary-school and university in the teaching of physics;

Motivating self-study;

Sorting out the problem of over-crowdedness in class;

$>$ The resolution of problems requires an effective policy which would integrate all teaching actors;

$>$ Openness on the learner by all the teaching actors in order to build mutual trust;

$>$ Revision of orientation methods by having suitable criteria so as to encourage The student to make the right choice.

\section{Journal Papers:}

\section{References}

[1]. Chakib,A.,Zahour,G.,Talbi,M.,Radid,M. Obstacles linguistiques liés à l'apprentissage des Sciences de la terre au Supérieur. Élaboration d'un didacticiel de traduction des termes géologiques «Lexigloss ».Revue EpiNet(EPI). (2013). https://www.epi.asso.fr/revue/articles/a1303c.htm [date de consultation 01/11/2O16]

[2]. Khyati,A.,Talbi,M.,Boumahmaza,M. 25ème colloque de l'ADMEE-Europe Fribourg : Evaluation et autoévaluation, quels espaces de formation, Former à l'évaluation des apprentissages en physique et chimie. (2013).

[3]. http://www.admee2013.ch/ADMEE-2013/7_files/Khyati-Abderrahim-ADMEE-2013.pdf

[4]. Mounia,S. FOS/FOU :Quel «français»pour les étudiants algériens des filières scientifiques ? (2011).

[5]. https://gerflint.fr/Base/Monde8-T2/sebane.pdf

[6]. G. Brouseau. Erreurs, difficultés, obstacles,(2003).

[7]. http://guy-brousseau.com/1659/erreurs-difficultes-obstacles-2003/

[8]. Touche,L .,et al.(2011).Transition lycee-universite, penser des dispositifs d'appui ,Revue internationale des technologies en pédagogie universitaire

[9]. https://edutice.archives-ouvertes.fr/edutice-00613839 [date de consultation 10/10/2016]

Theses:

[10]. R. Kasour, Etude épistémologique et didactique des obstacles et difficultés d'apprentissage d'algèbre linéaire, (2014) 59-67

Books:

[11]. Saint-Girons,B.,(2009),Pour une transition réussie du lycéé vers l'enseignement supérieur

[12]. http://www.ladocumentationfrancaise.fr/var/storage/rapports-publics/094000359.pdf 